\title{
Polymorphism of a widely used building block for halogen-bonded assemblies: 1,3,5-trifluoro-2,4,6-triiodobenzene
}

\author{
Pablo A. Raffo, Sebastián Suárez, Adolfo C. Fantoni, Ricardo Baggio and \\ Fabio D. Cukiernik
}

Acta Cryst. (2017). C73, 667-673

\begin{tabular}{|l|}
\hline IUCr Journals \\
CRYSTALLOGRAPHY JOURNALS ONLINE \\
Copyright C International Union of Crystallography \\
Author(s) of this paper may load this reprint on their own web site or institutional repository provided that \\
this cover page is retained. Republication of this article or its storage in electronic databases other than as \\
specified above is not permitted without prior permission in writing from the IUCr. \\
For further information see http://journals.iucr.org/services/authorrights.html
\end{tabular}


STRUCTURAL

CHEMISTRY

ISSN 2053-2296

Received 9 May 2017

Accepted 26 July 2017

Edited by H. Uekusa, Tokyo Institute of Technology, Japan

Keywords: additive-induced polymorphism; atoms in molecules (AIM); crystal structure; halogen bonding; noncovalent interactions; melting point; cohesion energy.

CCDC reference: 1564695

Supporting information: this article has supporting information at journals.iucr.org/c

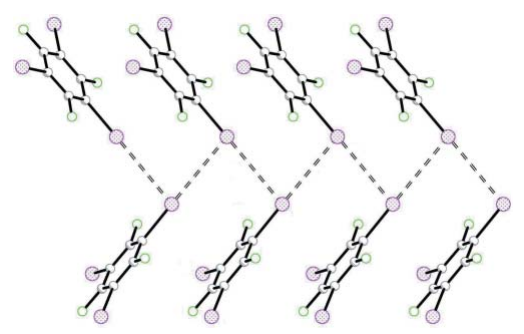

C 2017 International Union of Crystallography

\section{Polymorphism of a widely used building block for halogen-bonded assemblies: 1,3,5-trifluoro-2,4,6- triiodobenzene}

\author{
Pablo A. Raffo, ${ }^{\mathrm{a}, \mathrm{b}}$ Sebastián Suárez, ${ }^{\mathrm{a}, \mathrm{b}, \mathrm{c}}$ Adolfo C. Fantoni, ${ }^{\mathrm{d}}$ Ricardo Baggio ${ }^{\mathrm{c} *}$ and \\ Fabio D. Cukiernik ${ }^{\mathrm{a}, \mathrm{b} *}$
}

åDepartamento de Química Inorgánica, Analítica y Química Física, Facultad de Ciencias Exactas y Naturales, Universidad de Buenos Aires, Argentina, 'bnstituto de Química Física de los Materiales, Medio Ambiente y Energía, INQUIMAE, Universidad de Buenos Aires, CABA, Argentina, ${ }^{\mathbf{c}}$ Gerencia de Investigación y Aplicaciones, Centro Atómico Constituyentes, Comisión Nacional de Energía Atómica, Buenos Aires, Argentina, and Instituto de Física de La Plata, Departamento de Física, Facultad de Ciencias Exactas, Universidad Nacional de La Plata, Pcia de Buenos Aires, Argentina. *Correspondence e-mail: baggio@tandar.cnea.gov.ar, fabioc@qi.fcen.uba.ar

After reporting the structure of a new polymorph of 1,3,5-trifluoro-2,4,6triiodobenzene (denoted BzF3I3), $\mathrm{C}_{6} \mathrm{~F}_{3} \mathrm{I}_{3}$, (I), which crystallized in the space group $P 2_{1} / c$, we perform a comparative analysis with the already reported $P 2_{1} / n$ polymorph, (II) [Reddy et al. (2006). Chem. Eur. J. 12, 2222-2234]. In polymorph (II), type-II I $\cdots$ I halogen bonds and I $\cdots \pi$ interactions connect molecules in such a way that a three-dimensional structure is formed; however, the way in which molecules are connected in polymorph (I), through type-II I $\cdots$ I halogen bonds and $\pi-\pi$ interactions, gives rise to an exfoldable lamellar structure, which looks less tightly bound than that of (II). In agreement with this structural observation, both the melting point and the melting enthalpy of (I) are lower than those of (II).

\section{Introduction}

Polymorphic varieties of a given compound are of enormous interest in fields as diverse as pharmaceuticals, materials, basic crystallography and solid-state physical chemistry. Polymorphs can exhibit different physical properties, like solubility (Rajamma et al., 2015; Park et al., 2003), which can in turn determine their bioavailability and pharmacological efficiency (Hilfiker, 2006), melting point (Rajamma et al., 2015; Baldrighi et al., 2014; Thallapally et al., 2004), as well as magnetic (Šalitroš et al., 2016) or nonlinear optical (NLO) properties (Ruiz et al., 2007), which can be of interest for materials applications. From a physicochemical viewpoint, they represent examples of 'kinetic products' (least stable polymorph) versus 'thermodynamic products' (most stable polymorph) (Thallapally et al., 2004; Weissbuch et al., 2005; Sarkar et al., 2016; Resnati et al., 2015). Their relative stabilities usually arise from different noncovalent interaction patterns. The way the less stable polymorphs grow during the crystallization process, although not yet firmly understood, has been the subject of remarkable studies (Weissbuch et al., 2003, 2005; Torbeev et al., 2005; Thallapally et al., 2004). A combination of experimental and theoretical approaches sheds light on the key role the interactions of solvent molecules or other chemical species ('additives') with specific faces of the clusters formed during the early stages of the nucleation process play on the nature of the formed polymorph. Indeed, the widespread expressions 'solvent-induced polymorphism' and 
Table 1

Experimental details for (I) and (II).

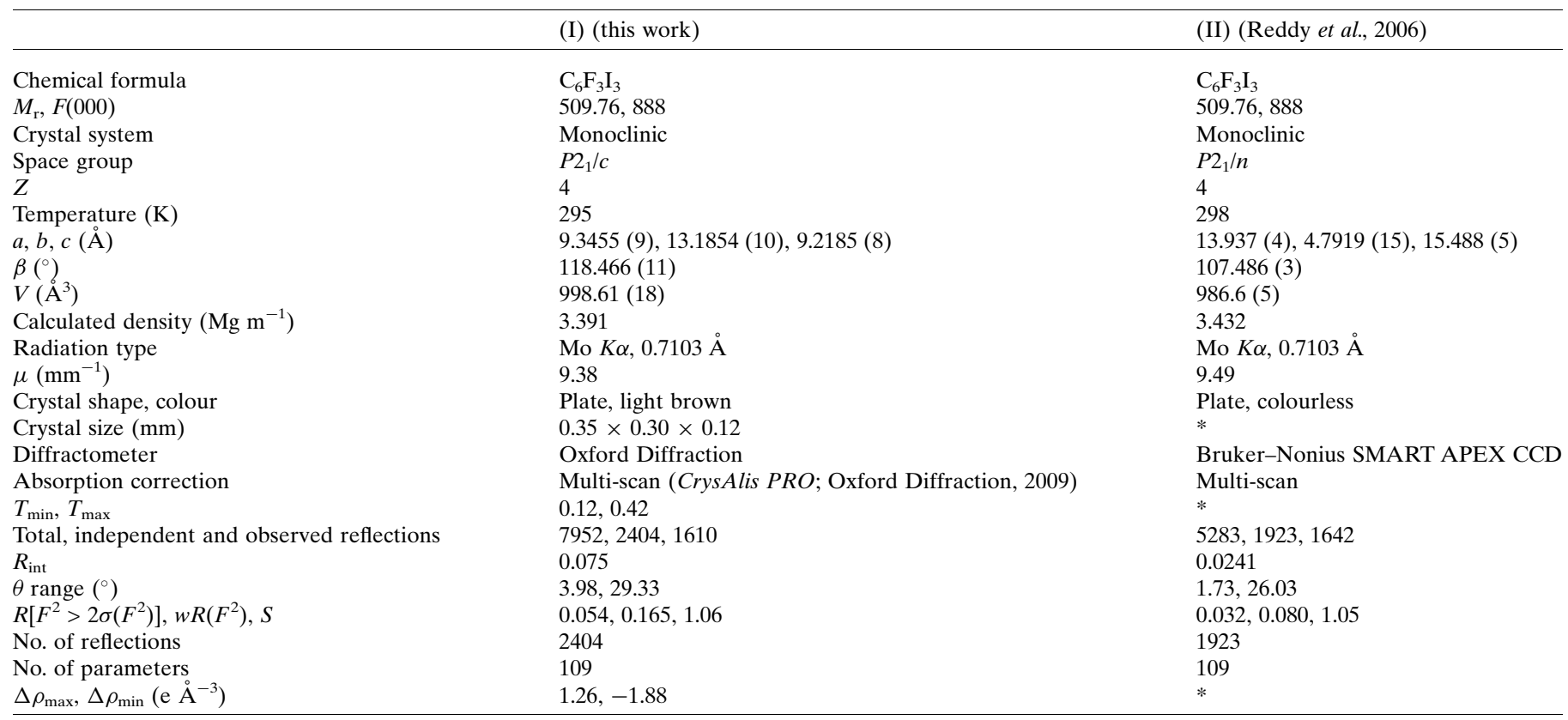

Note: $(*)$ information not available in the original publication.

'additive-induced polymorphism' refer to this recognized influence, even in a more phenomenological sense.

1,3,5-Trifluoro-2,4,6-triiodobenzene (BzF3I3) is a widely used building block in the crystal engineering of mixed assemblies based on donor-acceptor halogen bonds (Lucassen et al., 2007; Metrangolo et al., 2008; Aakeröy et al., 2014; Hidalgo et al., 2016). Indeed, the $\mathrm{C}-\mathrm{I}$ bonds in this molecule are subjected to strong polarization due to the presence of fluorine substituents, thus giving rise to a depletion of the electron density in the region of the I atom opposite to the $\mathrm{C}-\mathrm{I}$ bond. This electropositive region is called the ' $\sigma$-hole' (Politzer et al., 2013), and acts as the electrophile when interacting with nucleophiles like nitrogenated bases (pyridine derivatives, etc.). This kind of interaction belongs to the 'traditional' donor-acceptor halogen bonds (Cavallo et al., 2016). In recent years, type-II $X \cdots X$ contacts $(X=\mathrm{Cl}, \mathrm{Br}, \mathrm{I})$ have been accepted as donor-acceptor halogen bonds; the electron-rich 'belt' around one $X$ atom acts as the nucleophile toward the $\sigma$-hole of the other $X$ atom (Metrangolo \& Resnati, 2014). BzF3I3 can thus exhibit halogen bonds not only in cocrystals with nitrogenated bases, but also in its own crystalline structure. Indeed, the already reported $P 2_{1} / n$ polymorph of BzF3I3 exhibits such interactions, with a ladder pattern also being found in compounds like bromobenzamide, bromobenzoic acids, etc.

During the course of our studies aimed at cocrystallizing BzF3I3 with amines bearing mid-length aliphatic chains, as a step toward halogen-bound discotic supramolecular liquid crystals, we fortuitously obtained a new polymorph of BzF3I3 (space group $P 2_{1} / c$ ). We describe herein the structure of the new polymorph, (I), and perform a comparative analysis with the $P 2_{1} / n$ polymorph, (II). We shall discuss differences and similarities, and the role fulfilled in the packing arrangement by the profuse set of $\pi-\pi, \mathrm{C}-X \cdots \pi$ and $\mathrm{C}-X \cdots X^{\prime}-\mathrm{C}^{\prime}(X=$ $\mathrm{F}, \mathrm{I})$ noncovalent interactions present. In addition, we shall discuss the latter at the light of Bader's theory of Atoms In Molecules (AIM) and computational estimations of the respective cohesion energies, and compare this analysis with experimental measurements related to structure cohesion, like melting points and enthalpies.<smiles>[13CH3]c1c(F)c(I)c(F)c(I)c1F</smiles>

\section{Experimental}

\subsection{Synthesis and crystallization}

BzF3I3 was synthesized from 1,3,5-trifluorobenzene (Aldrich, used without further purification) according to the method of Raffo et al. (2015), which involves slight modifications to the Sander's method (Wenk \& Sander, 2002). It has been characterized by ${ }^{13} \mathrm{C}$ NMR $[\delta 63.9(d t)$ and $162.4(d t)]$, FT-IR [ $v$ in $\mathrm{cm}^{-1}: 1564(s), 1406(s), 1326(m), 1050(s), 705$ $(m)$ and $654(s)]$ and elemental analysis [C\%, found (calculated): 14.1 (14.14)]. Single crystals of polymorph (I) were obtained by dissolving BzF3I3 (50.2 $\mathrm{mg}, 0.098 \mathrm{mmol}$ ) and dibutylamine $(0.140 \mathrm{ml})$ in tetrahydrofuran (THF; $2.0 \mathrm{ml})$, then allowing the solvent to evaporate slowly by diffusion in liquid paraffin. Plate-like single crystals were collected after complete THF evaporation ( $c a$ two months). 
Figure 1

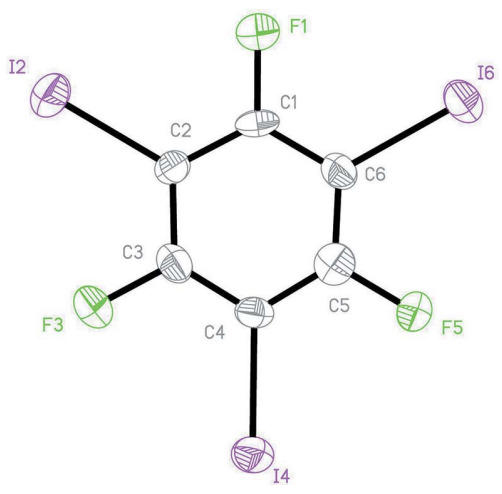

A displacement ellipsoid plot of (I) (50\% probability level), showing the (common) labelling scheme used.

\subsection{Physicochemical measurements}

Elemental analysis was carried out at Servicio a Terceros of INQUIMAE on a Carlo Erba CHNS-O EA1108 analyzer. ${ }^{13} \mathrm{C}$ NMR spectra were measured at UMYMFOR on a Bruker AM500 spectrometer, using $\mathrm{CDCl}_{3}$ as solvent and its peak as internal reference [77.2 $(t)$ ppm for ${ }^{13} \mathrm{C}$ ]. Differential scanning calorimetry (DSC) was performed with a Shimadzu DSC-50 apparatus.

\subsection{Resolution, refinement and analysis}

Comparative crystal data, data collection and structure refinement details for (I) and (II) are summarized in Table 1. The computer programs used were CrysAlis PRO (Oxford Diffraction, 2009) for data collection and data reduction, SHELXS97 (Sheldrick, 2008) for structure resolution, SHELXL2014 (Sheldrick, 2015) for structure refinement, XP in SHELXTL (Sheldrick, 2008) for molecular graphics and PLATON (Spek, 2009) for structural analysis. Full use was made of the Cambridge Structural Database (CSD, Version 5.38 and upgrades; Groom et al., 2016). It is worth noting that the present structure, albeit being eminently 'organic', does not include any $\mathrm{H}$ atoms.

\subsection{Computational calculations}

Quantum-mechanical calculations were performed at the PBEPBE-D/DGDZVP level of theory using the crystallographic coordinates (single-point calculations) within the GAUSSIAN09 program (Frisch et al., 2009). This level of theory includes available dispersion correction (D3) and diffuse functions in the basis set and is adequate for studying noncovalent interactions dominated by dispersion effects, like, for instance, $\pi$-stacking (Foi et al., 2014; Wang et al., 2016). The basis set superposition error (BSSE) for the calculation of

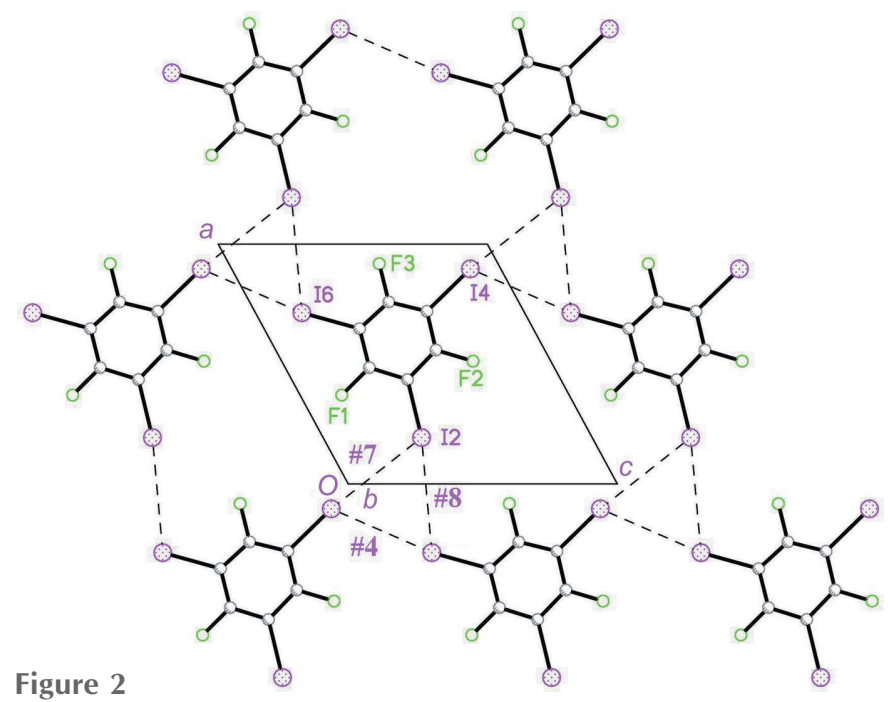

View of the (010) plane in (I). Interaction codes are as in Table 4.

interaction energies was corrected using the counterpoise method (estimated relative error for the energies $<5 \%$ ) (Liu \& McLean, 1973; Jansen \& Ros, 1969; van Duijneveldt et al., 1994). In addition, AIM analysis of the electron density has been performed at the same level of theory using the Multiwfn program (Lu \& Chen, 2012).

Periodic calculations were carried out with the CRYSTAL14 package (Dovesi et al., 2014) using the B3LYP hybrid functional, 6-31G** or TZVP (Peintinger et al., 2012) basis sets for C and F atoms, and the Doll's (Doll \& Stoll, 1998) or HAYWLC (Prencipe, 1990) basis sets for I atoms. The basis set $6-31 \mathrm{G}^{* *}$ proved adequate for exploring other related systems exhibiting halogen bonds (Ellman, 2006; Raffo et al., 2016; Rosokha et al., 2013) and was found to yield cohesion energies very similar to those obtained through the use of other basis sets like TZP (Civalleri et al., 2008). With I atoms, bigger basis sets were required, so the Doll's (Pham et al., 2014) or HAYWLC basis sets were used. Long-range dispersion contributions were taken into account by including a London-type pairwise empirical correction (Civalleri et al., 2008). A BSSE correction was used in the calculation of lattice energies.

\section{Results and discussion}

Fig. 1 shows a displacement ellipsoid plot for (I), disclosing the atom-labelling scheme used (common to both structures). Tables 2, 3 and 4 show the $\pi-\pi, \mathrm{C}-X \cdots \pi$ and $\mathrm{C}-X \cdots X^{\prime}-\mathrm{C}^{\prime}$ $(X=\mathrm{F}, \mathrm{I})$ interactions for the new polymorph (I), while Tables 5 and 6 , in turn, show the $\mathrm{C}-X \cdots \pi$ and $\mathrm{C}-X \cdots X^{\prime}-\mathrm{C}^{\prime}$ contacts for already reported polymorph (II). The first column

Table 2

$\pi-\pi$ interaction for (I).

\begin{tabular}{lllllllll}
\hline Code & Type & $C g \cdots C g$ & $C g \cdots C g(\AA)$ & da $\left({ }^{\circ}\right)$ & $d /$ perp $(\AA)$ & Shift $(\AA)$ & $100 * \rho\left(r_{\mathrm{CP}}\right)($ a.u. $)$ & $100 * \nabla^{2} \rho\left(r_{\mathrm{CP}}\right)($ a.u. $)$ \\
\hline$\# 1$ & $\mathbf{A}-\mathbf{A}$ & $C g 1 \cdots C g 1^{\mathrm{i}}$ & $3.859(7)$ & $0.0(5)$ & $3.531(4)$ & 1.557 & 0.40 & 0.13 \\
\hline
\end{tabular}

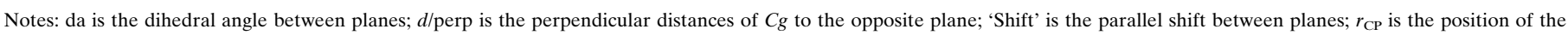
critical point. Type code: $\mathbf{A}-\mathbf{A}=$ linking faces type $\mathbf{A}$. Symmetry code: (i) $-x+1,-y+2,-z+1$. 
Table 3

$\mathrm{C}-X \cdots \pi$ interactions for $(\mathrm{I})(X=\mathrm{F}, \mathrm{I})$.

\begin{tabular}{|c|c|c|c|c|c|c|c|c|}
\hline Code & Type & $\mathrm{C}-X \cdots C g$ & $X \cdots C g(\AA)$ & $X / \operatorname{perp}(\AA)$ & $X \cdots C g /$ perp $\left(^{\circ}\right)$ & $\mathrm{C}-X /$ perp $\left(^{\circ}\right)$ & $100 * \rho\left(r_{\mathrm{CP}}\right)$ (a.u.) & $100 * \nabla^{2} \rho\left(r_{\mathrm{CP}}\right)$ (a.u.) \\
\hline \#2 & B-B & $\mathrm{C} 6-\mathrm{I} 6 \cdots C g 1^{\mathrm{ii}}$ & 4.308 (3) & 3.797 (3) & $28.1(2)$ & $69.8(2)$ & 0.50 & 0.14 \\
\hline \#3 & B-B & $\mathrm{C} 3-\mathrm{F} 3 \cdots C g 1^{\mathrm{iii}}$ & $3.663(6)$ & 3.109 (7) & $30.8(2)$ & $111.3(3)$ & 0.49 & 0.20 \\
\hline
\end{tabular}

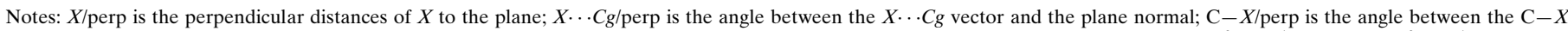
vector and the plane normal; $r_{\mathrm{CP}}$ is the position of the critical point. Type code: $\mathbf{B}-\mathbf{B}=$ linking faces type $\mathbf{B}$. Symmetry codes: (ii) $x,-y+\frac{3}{2}, z-\frac{1}{2}$; (iii) $x,-y+\frac{3}{2}, z+\frac{1}{2}$.

Table 4

$\mathrm{C}-X \cdots X^{\prime}-\mathrm{C}^{\prime}$ interactions for $(\mathrm{I})(X=\mathrm{F}, \mathrm{I})$.

\begin{tabular}{|c|c|c|c|c|c|c|c|}
\hline Code & Type & $\mathrm{C}-X \cdots(X-\mathrm{C})^{\prime}$ & $X \cdots X^{\prime}(\AA)$ & $<\mathrm{C}-X \cdots X^{\prime}>\left(^{\circ}\right)$ & $<X \cdots X^{\prime}-\mathrm{C}^{\prime}>\left(^{\circ}\right)$ & $100 * \rho\left(r_{\mathrm{CP}}\right)$ (a.u.) & $100 * \nabla^{2} \rho\left(r_{\mathrm{CP}}\right)$ (a.u.) \\
\hline \#4 & $\boldsymbol{X}$ & $\mathrm{C} 4-\mathrm{I} 4 \cdots(\mathrm{I} 6-\mathrm{C} 6)^{\mathrm{iv}}$ & $3.8341(15)$ & $111.3(3)$ & $157.4(3)$ & 0.93 & 0.22 \\
\hline \#5 & B-B & $\mathrm{C} 2-\mathrm{I} 2 \cdots(\mathrm{I} 4-\mathrm{C} 4)^{\mathrm{v}}$ & $3.9264(14)$ & $143.3(3)$ & $100.3(3)$ & 0.86 & 0.20 \\
\hline \#6 & $\mathbf{A}-\mathbf{A}$ & $\mathrm{C} 4-\mathrm{I} 4 \cdots(\mathrm{I} 4-\mathrm{C} 4)^{\mathrm{vi}}$ & $4.0610(12)$ & $118.1(3)$ & $118.1(3)$ & 0.73 & 0.17 \\
\hline$\# 8$ & $\boldsymbol{X}$ & $\mathrm{C} 2-\mathrm{I} 2 \cdots(\mathrm{I} 6-\mathrm{C} 6)^{\mathrm{viii}}$ & $4.1271(15)$ & $152.3(4)$ & $106.5(4)$ & 0.42 & 0.11 \\
\hline \#9 & B-B & $\mathrm{C} 2-\mathrm{I} 2 \cdots(\mathrm{F} 1-\mathrm{C} 1)^{\mathrm{iii}}$ & $3.7852(13)$ & $83.2(4)$ & $126.1(4)$ & 0.38 & 0.12 \\
\hline$\# 10$ & B-B & $\mathrm{C} 4-\mathrm{I} 4 \cdots(\mathrm{F} 5-\mathrm{C} 5)^{\mathrm{iii}}$ & $3.8683(14)$ & $109.6(3)$ & $86.9(3)$ & 0.36 & 0.12 \\
\hline
\end{tabular}

Notes: $<\mathrm{C}-X \cdots X^{\prime}>$ is the angle between the $\mathrm{C}-X$ and $X \cdots X^{\prime}$ vectors; $<X \cdots X^{\prime}-\mathrm{C}^{\prime}>$ is the angle between the $X \cdots X^{\prime}$ and $X^{\prime}-\mathrm{C}^{\prime}$ vectors; $r_{\mathrm{CP}}$ is the position of the critical point. Type

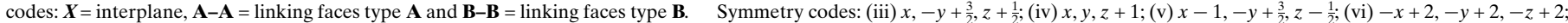
(vii) $x-1, y, z-1$; (viii) $x-1, y, z$.

in these tables includes a sequence interaction number, for convenience of description, and the last two columns, include relevant parameters from AIM calculations. ${ }^{1}$

The elemental structural unit in new polymorph (I) appears to be the two-dimensional substructure parallel to (010), shown in Fig. 2. The two-dimensional substructure is stabilized by three 'in-plane' $\mathrm{C}-\mathrm{I} \cdots \mathrm{I}^{\prime}-\mathrm{C}^{\prime}$ interactions, labelled as \#4 (the most relevant, according to AIM parameters), \#7 and \#8 in Table 4, which can be considered type-II I...I halogen bonds building up a cyclic I3 synthon (Bui et al., 2009).

These planes pile up along the $b$ axis in an antiparallel fashion, neighbouring planes being generated by the inversion centres (thus confronting faces labelled $\mathbf{A}$ in Fig. 3) or the glide plane (thus confronting faces labelled $\mathbf{B}$ in Fig. 3). The set of $\mathbf{A}-\mathbf{A}$ and $\mathbf{B}-\mathbf{B}$ interactions are different, as are their effect in defining the least-squares interplanar distances

\footnotetext{
${ }^{1}$ AIM (an acronym for the 'Atoms In Molecules' theory; Bader, 1990, 2009) interprets chemical bonding in terms of shared or closed-shell interactions, characterized by the electron density $[\rho(r)]$, its gradient vector $[\nabla \rho(r)]$ and its Laplacian $\left[\nabla^{2} \rho(r)\right]$ at particular points termed 'bond critical points', where the sign and magnitude of $\rho(r)$ and $\nabla^{2} \rho(r)$ define the interaction type. AIM has been a matter of debate on theoretical grounds [viz. Haaland et al., (2004), Poater et al., (2006) and Krapp \& Frenking (2007) versus Bader (2009)] and continues to be a controversial issue [Dunitz (2015) versus Thakur et al. (2015) and Lecomte et al. (2015)]. Even if now accepted as an extremely valuable means of disclosing and characterizing interactions, some critical viewpoints concerning the application of the method (when 'absolute' AIM values are analyzed) have been raised (Spackman, 2015), but its use as a tool for 'relative' comparisons is steadily gaining general acceptability (Wang et al., 2016, etc.). In the present case, we established a well-defined correlation between the AIM parameters and the interaction energies. Indeed, we calculated the energy of several 'dimers' found in the structures (as the difference between the energy of the dimer and twice that of the isolated molecules) and used these results in order to identify the critical points. The results of these calculations are presented for both polymorphs in Fig. S1 of the supporting information. In each of these dimers, one or more interactions might been involved; nevertheless, one of them can be often considered as predominant. The excellent correlation between the calculated energy of such dimeric units and the corresponding AIM parameters can be assessed in Fig. S2 of the supporting information.
}

[A-A = 3.212 (2) $\AA$ and $\mathbf{B}-\mathbf{B}=3.381$ (2) $\AA$ ] . In the first group appear interactions \#1 and \#6 (Tables 2 and 4), and in the second, interactions \#2, \#3, \#5, \#9 and \#10 (Tables 3 and 4, and Fig. 2).

In turn, the more striking building blocks in the structure of polymorph (II) are the columns shown in Fig. 4, running along the $b$ axis and built up by parallel molecules shifted by a [010] vector, and oriented at a rather large angle $\left(\sim 41.1^{\circ}\right)$ to the columnar axis. Even if the interplanar distance [3.604 (3) $\AA$ ] is compatible with the existence of stacking interactions, this is disrupted by the almost 'one-molecule-wide' slippage (3.160 ̊) due to the large slanting angle. But, on the other hand, this very tilted orientation favours the occurrence of two different $\mathrm{C}-X \cdots \pi$ contacts (interactions \#1 and \#2 in Table 5). Note the rather 'straight' $X \cdots \pi$ vectors (departures from the vertical by $\sim 12^{\circ}$ ), as well as the almost 'horizontal'

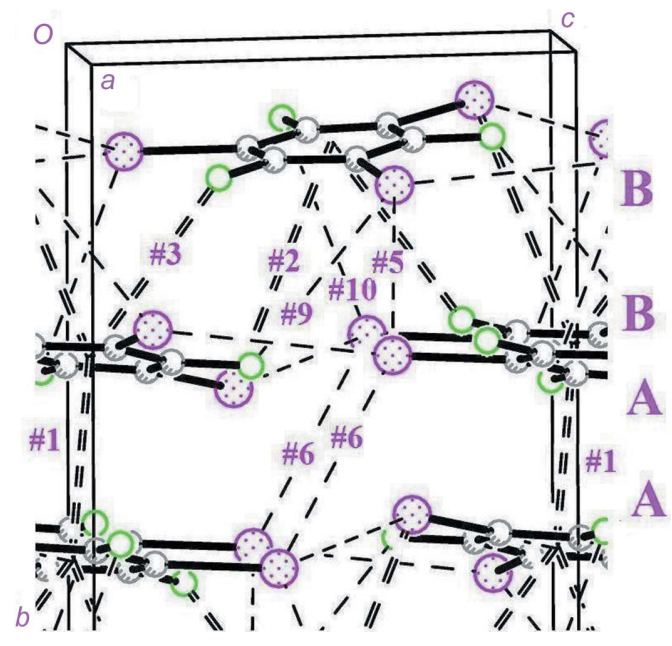

Figure 3

The stacking of planes in polymorph (I) in a detailed view showing labelled interactions. Interaction codes are as in Tables 2, 3 and 4. 
Table 5

$\mathrm{C}-X \cdots \pi$ interactions for (II) $(X=\mathrm{F}, \mathrm{I})$.

\begin{tabular}{lllllllll}
\hline Code & Type & $\mathrm{C}-X \cdots C g$ & $X \cdots C g(\AA)$ & $X /$ perp $(\AA)$ & $X \cdots C g /$ perp $\left(^{\circ}\right)$ & C $-X /$ perp $\left(^{\circ}\right)$ & $100 * \rho\left(r_{\mathrm{CP}}\right)($ a.u. $)$ & $100 * \nabla^{2} \rho\left(r_{\mathrm{CP}}\right)($ a.u. $)$ \\
\hline$\# 1$ & $\boldsymbol{X}$ & $\mathrm{C} 2-\mathrm{I} 2 \cdots C g 1^{\mathrm{i}}$ & $3.728(3)$ & 3.642 & 12.29 & $83.1(2)$ & 0.69 & 0.21 \\
$\# 2$ & $\boldsymbol{X}$ & $\mathrm{C}-\mathrm{F} 5 \cdots C g 1^{\mathrm{ii}}$ & $3.663(6)$ & 3.575 & 12.66 & $82.7(4)$ & 0.48 & 0.19 \\
\hline
\end{tabular}

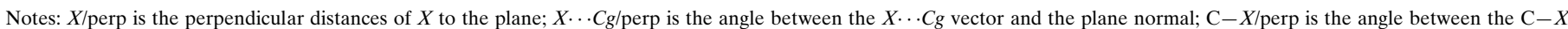
vector and the plane normal; $r_{\mathrm{CP}}$ is the position of the critical point. Type code: $\boldsymbol{X}=$ intra-column. Symmetry codes: (i) $x, y+1, z$; (ii) $x, y-1, z$.

Table 6

$\mathrm{C}-X \cdots X^{\prime}-\mathrm{C}^{\prime}$ interactions for (II) $(X=\mathrm{F}, \mathrm{I})$.

\begin{tabular}{|c|c|c|c|c|c|c|c|}
\hline Code & Type & $\mathrm{C}-X \cdots(X-\mathrm{C})^{\prime}$ & $X \cdots X^{\prime}$ & $<\mathrm{C}-X \cdots X^{\prime}>\left(^{\circ}\right)$ & $<X \cdots X^{\prime}-\mathrm{C}^{\prime}>\left(^{\circ}\right)$ & $100 * \rho\left(r_{\mathrm{CP}}\right)$ (a.u.) & $100 * \nabla^{2} \rho\left(r_{\mathrm{CP}}\right)$ (a.u.) \\
\hline$\# 3$ & $\mathbf{Y}$ & $\mathrm{C} 2-\mathrm{I} 2 \cdots(\mathrm{I} 2-\mathrm{C} 2)^{\mathrm{iii}}$ & $3.774(2)$ & $171.1(2)$ & $100.7(2)$ & 1.02 & 0.24 \\
\hline \#4 & $\mathbf{Z}$ & $\mathrm{C} 4-\mathrm{I} 4 \cdots(\mathrm{I} 6-\mathrm{C} 6)^{\mathrm{iv}}$ & $3.957(2)$ & $80.5(5)$ & $146.8(5)$ & 0.80 & 0.19 \\
\hline \#5 & $\mathbf{Z}$ & $\mathrm{C} 6-\mathrm{I} 6 \cdots(\mathrm{I} 6-\mathrm{C} 6)^{\mathrm{v}}$ & $4.101(2)$ & $138.4(2)$ & $138.4(2)$ & 0.57 & 0.14 \\
\hline$\# 7$ & $\boldsymbol{X}$ & $\mathrm{C} 1-\mathrm{F} 1 \cdots(\mathrm{I} 6-\mathrm{C} 6)^{\mathrm{i}}$ & $3.656(5)$ & $87.3(4)$ & $90.4(4)$ & 0.53 & 0.17 \\
\hline \#8 & $\mathbf{Z}$ & $\mathrm{C} 3-\mathrm{F} 3 \cdots(\mathrm{F} 3-\mathrm{C} 3)^{\mathrm{vii}}$ & $2.851(8)$ & $157.4(5)$ & $157.4(5)$ & 0.52 & 0.28 \\
\hline$\# 9$ & $\mathbf{Z}$ & $\mathrm{C} 1-\mathrm{F} 1 \cdots(\mathrm{I} 4-\mathrm{C} 4)^{\mathrm{vii}}$ & $3.584(5)$ & $145.5(4)$ & $126.1(4)$ & 0.49 & 0.17 \\
\hline$\# 10$ & $\mathbf{Z}$ & $\mathrm{C} 5-\mathrm{F} 5 \cdots(\mathrm{I} 6-\mathrm{C} 6)^{\mathrm{vii}}$ & $3.530(5)$ & $167.3(4)$ & $74.2(4)$ & 0.41 & 0.13 \\
\hline
\end{tabular}

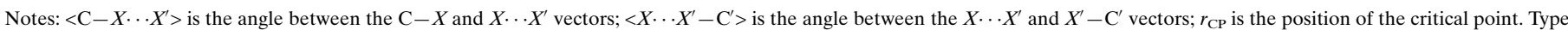

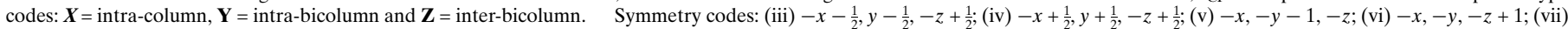
$x-\frac{1}{2},-y+\frac{1}{2}, z-\frac{1}{2} ;$ (viii) $-x+\frac{1}{2}, y-\frac{1}{2},-z+\frac{1}{2}$.

$\mathrm{C}-X \cdots \pi$ ones $\left(\right.$ angles of $\sim 83^{\circ}$ ), an arrangement which approaches that expected for a donor-acceptor $\mathrm{C}-X \cdots \pi$ interaction, with the negative 'belt' around $X$ pointing to the positively charged zone at the ring centre. There is a further $\mathrm{C}-\mathrm{F}$...I-C interaction (\#7 in Table 6) reinforcing the columnar strength. AIM calculations ascribe these three interactions a 'medium-strength' character (Wang et al., 2016; Di Paolo et al., 2016).

The strongest linkage in structure (II) is found between neighbouring columns related by the $2_{1}$ axis, through a single zigzag $\mathrm{C}-\mathrm{I} \cdots \mathrm{I}-\mathrm{C}$ interaction (\#3 in Table 6 and Figs. 5 and $6)$. This type of contact has already been observed in halogenated aromatic compounds as $\mathrm{Br}$-benzamide (Tothadi et al., 2013), Br-benzoic acids (Ohkura et al., 1972; Raffo et al., 2016), etc. In the present case, the effect is that of 'threading' parallel columns into a strongly bound 'bi-columnar' unit. Due to the $2_{1}$ relationship between the two columns, with a $41.1^{\circ}$ slanting angle to the $b$ axis, molecules in each end up being almost perpendicular $\left(2 \times 41.1^{\circ}=82.2^{\circ}\right)$. These one-dimensional structures along the $b$ axis are finally interlinked with their parallel neighbours by a plethora of $\mathrm{C}-X \cdots X^{\prime}-\mathrm{C}^{\prime}$ noncovalent bonds of different types and strengths, presented

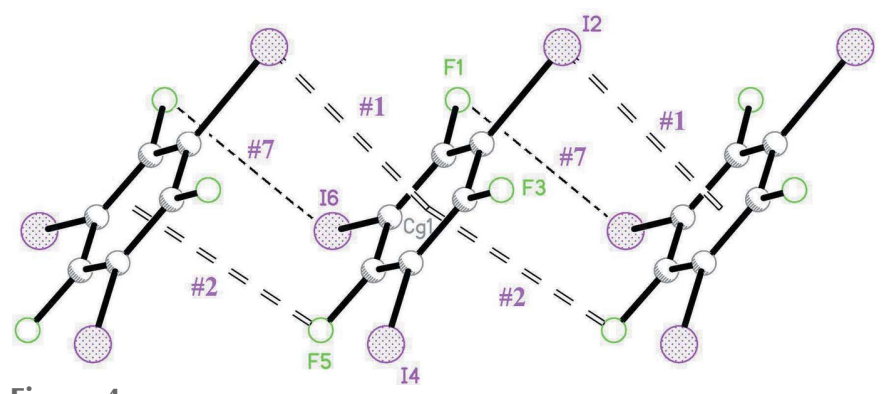

Figure 4

The columnar array in (II). Interaction codes are as in Tables 5 and 6 . in Table 6. Fig. 6 displays in projection one central column (in strong black lining), emphasizing the lateral interactions which link it to six different neighbouring columns in a strongly linked three-dimensional structure.

In their detailed study on the structures of hexahalogenated benzenes, Desiraju and co-workers (Reddy et al., 2006) found layered structures similar to that exhibited by polymorph (I) for the triclinic forms of some derivatives, such as 1,3,5-tribromotriiodobenzene (BzB3I3); they pointed out that these structures were based on strong triangular I3 synthons exhibiting very short I …I distances (3.75-3.80 ̊). For BzF3I3, they only found the already analysed three-dimensional monoclinic (II) polymorph, and predicted that the F..F distances in an eventual layered structure should amount to $5.01 \AA$ A. Certainly, polymorph (I) grew in our experiments due to the presence of dibutylamine, which acted as a 'nontaylored' additive-inductor of polymorphism. It exhibits the same

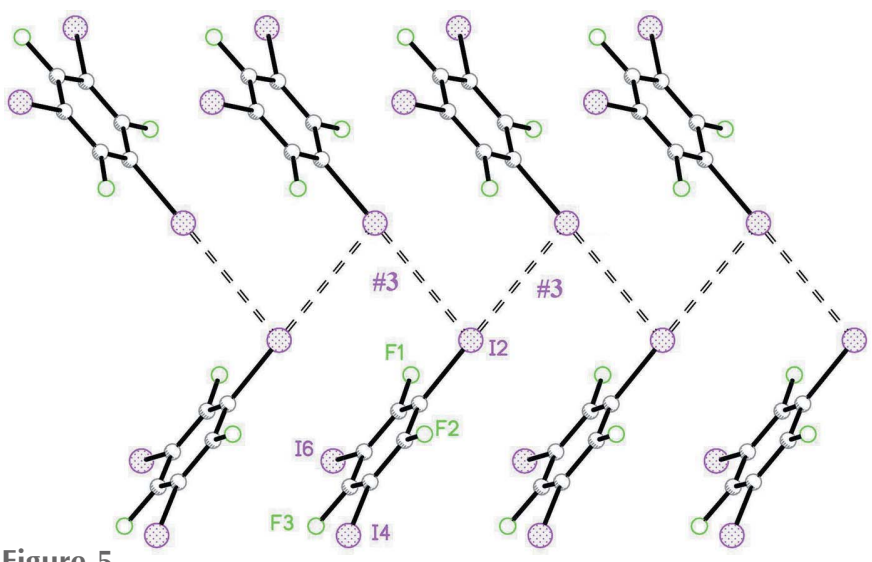

Figure 5

The linkage between neighbouring columns in (II), forming a 'bi-column'. Interaction codes are as in Table 6. 

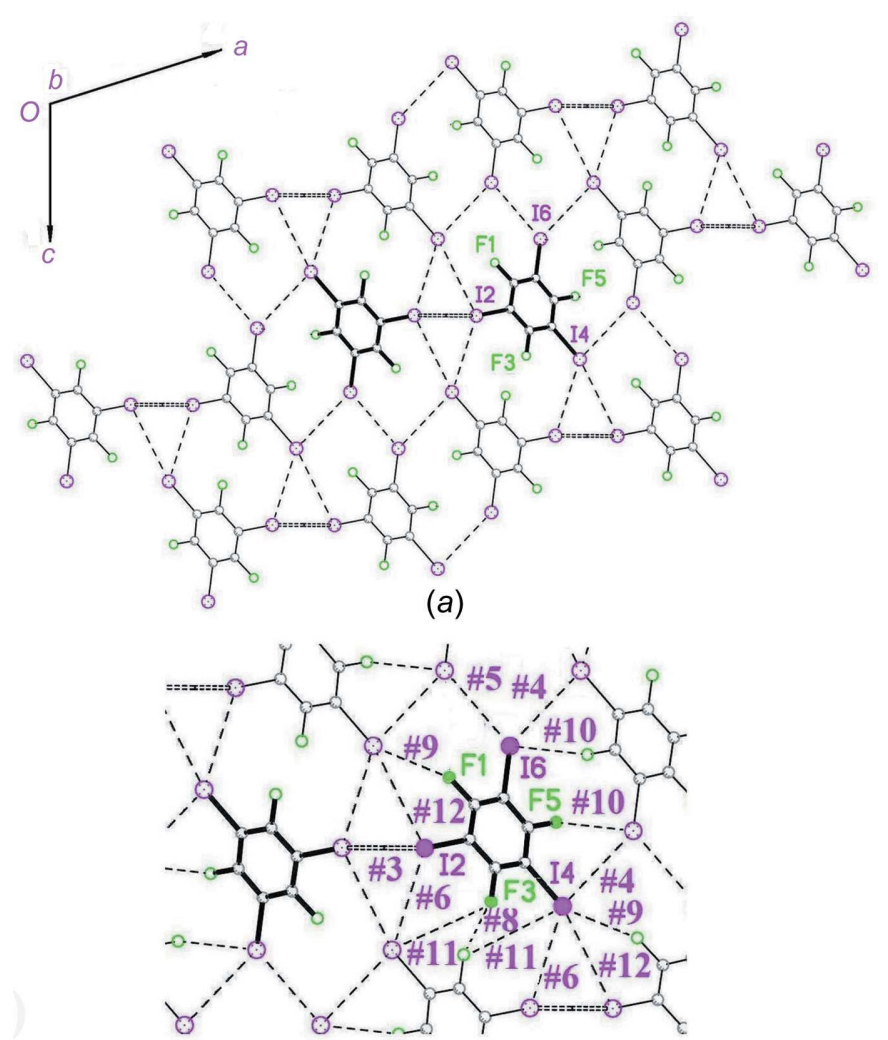

(b)

Figure 6

(a) A [010] view of (II), showing a 'bi-column' (in heavy lining) surrounded by its six neighbouring equivalents. For the sake of clarity, $\mathrm{C}-\mathrm{F} \cdots \mathrm{I} / \mathrm{F}-\mathrm{C}$ interactions are not shown. (b) The central 'bi-column' above (in heavy lining), with the full set of interactions labelled using the codes shown in Table 6. Only contacts where the reference atoms take part (acting either as donors or acceptors) are shown.

kind of I3 synthon, although with longer I . . I distances (range 3.83-4.13 A). Interestingly, the experimental F...F distances we found in the layered structure of (I) are 5.099 (11) (F3 - . F5), 5.095 (10) (F1‥F5) and 4.900 (12) $\AA$ (F1‥F3), in excellent agreement with Desiraju's prediction.

An examination of the global structure (three-dimensional versus two-dimensional), as well as the geometrical aspects of the main interactions found for both polymorphs [ $\theta 1$ and $\theta 2$ values closer to the values of 180 and $90^{\circ}$ expected for type-II halogen bonds, as well as shorter I . . I distances for polymorph (II)] suggests cohesion in polymorph (II) is higher than in (I). AIM analysis also points to the I. . I interactions being stronger in polymorph (II) than in (I). Although the comparison in the present terms is restricted to the stated directional interactions, many other directional and nondirectional interactions also play a role in the structure cohesion (as also evidenced by the AIM parameters).

In an attempt to validate this qualitative analysis, we performed quantum calculations of the respective cohesion energies for polymorphs (I) and (II) using the CRYSTAL14 package (Dovesi et al., 2014). These calculations provide cohesion energies quite similar for (I) and (II), independently of the basis sets used and in all cases within the range -94 to $105 \mathrm{~kJ} \mathrm{~mol}^{-1}$ (see Table S1 of the supporting information for individual values). Nevertheless, differential scanning calorimetry (DSC) provided experimental support for the stated relative stabilities. Indeed, DSC runs conducted on powdered samples of (II) and individual single crystals of (I) showed polymorph (II) melts at 428 (1) $\mathrm{K}$, with $\Delta H=19$ (2) $\mathrm{kJ} \mathrm{mol}^{-1}$, whereas polymorph (I) melts at $413(2) \mathrm{K}$, with $\Delta H=$ $11(4) \mathrm{kJ} \mathrm{mol}^{-1}$ (uncertainties quoted on the basis of the dispersion observed in different experiments). Both the melting point and the melting enthalpies indicate that polymorph (II) exhibits a more tightly organized structure than (I), in line with both our calculations and our crystallographic analysis of both structures.

\section{Funding information}

Funding for this research was provided by: Agencia Nacional de Promoción Científica y Tecnológica (grant No. PME 01113); UBACyT (grant No. 20020130100776BA); CONICET (grant No. PIP 201101-01035; postdoctoral fellowship to SS and $\mathrm{PhD}$ fellowship to PAR).

\section{References}

Aakeröy, C. B., Wijethunga, T. K. \& Desper, J. (2014). CrystEngComm, 16, 28-31.

Bader, R. F. W. (1990). In Atoms in Molecules - a Quantum Theory. Oxford University Press.

Bader, R. F. W. (2009). J. Phys. Chem. A, 113, 10391-10396.

Baldrighi, M., Bartesaghi, D., Cavallo, G., Chierotti, M. L., Gobetto, R., Metrangolo, P., Pilati, T., Resnati, G. \& Terraneo, G. (2014). CrystEngComm, 16, 5897-5904.

Bui, T. T. T., Dahaoui, S., Lecomte, C., Desiraju, G. R. \& Espinosa, E. (2009). Angew. Chem. Int. Ed. Engl. 48, 3838-3841.

Cavallo, G., Metrangolo, P., Milani, R., Pilati, T., Priimagi, A., Resnati, G. \& Terraneo, G. (2016). Chem. Rev. 116, 2478-2601.

Civalleri, B., Zicovich-Wilson, C. M., Valenzano, L. \& Ugliengo, P. (2008). CrystEngComm, 10, 405-410.

Di Paolo, M., Bossi, M. L., Baggio, R. \& Suarez, S. A. (2016). Acta Cryst. B72, 684-692.

Doll, K. \& Stoll, H. (1998). Phys. Rev. B, 57, 4327-4331.

Dovesi, R., Saunders, V. R., Roetti, C., Orlando, R., Zicovich-Wilson, C. M., Pascale, F., Civalleri, B., Doll, K., Harrison, N. M., Bush, I. J., D'Arco, Ph., Llunell, M., Causà, M. \& Noël, Y. (2014). CRYSTAL14 User's Manual. University of Torino, Torino, Italy.

Duijneveldt, F. B. van, van Duijneveldt-van de Rijdt, J. G. C. M. \& van Lenthe, J. H. (1994). Chem. Rev. 94, 1873-1885.

Dunitz, J. D. (2015). IUCrJ, 2, 157-158.

Ellman, B. (2006). J. Chem. Phys. 125, 074702-4.

Foi, A., Corrêa, R. S., Ellena, J., Doctorovich, F. \& Di Salvo, F. (2014). J. Mol. Struct. 1059, 1-7.

Frisch, M. J., et al. (2009). GAUSSIAN09. Gaussian Inc., Wallingford, CT, USA. http://www.gaussian.com.

Groom, C. R., Bruno, I. J., Lightfoot, M. P. \& Ward, S. C. (2016). Acta Cryst. B72, 171-179.

Haaland, A., Shorokhov, D. J. \& Tverdova, N. V. (2004). Chem. Eur. J. 10, 4416-4421.

Hidalgo, P. I., Leal, S., Jiménz, C. A., Vöhringer-Martínez, E., Herrera, B., Pasán, J., Ruiz-Pérez, C. \& Bruce, D. W. (2016). CrystEngComm, 18, 42-47.

Hilfiker, R. (2006). Editor. Polymorphism in the Pharmaceutical Industry. Weinheim: Wiley-VCH.

Jansen, H. B. \& Ros, P. (1969). Chem. Phys. Lett. 3, 140-143.

Krapp, A. \& Frenking, G. (2007). Chem. Eur. J. 13, 8256-8270.

Lecomte, C., Espinosa, E. \& Matta, C. F. (2015). IUCrJ, 2, 161-163. Liu, B. \& McLean, A. D. (1973). J. Chem. Phys. 59, 4557-4558. 
Lu, T. \& Chen, F. (2012). J. Comput. Chem. 33, 580-592.

Lucassen, A. C. B., Karton, A., Leitus, G., Shinon, L. J. W., Martin, J. M. L. \& van der Boom, M. E. (2007). Cryst. Growth Des. 7, 386392.

Metrangolo, P., Meyer, F., Pilati, T., Resnati, G. \& Terraneo, G. (2008). Chem. Commun. pp. 1635-1637.

Metrangolo, P. \& Resnati, G. (2014). IUCrJ, 1, 5-7.

Ohkura, K., Kashino, S. \& Haisa, M. (1972). Bull. Chem. Soc. Jpn, 45, 2651-2652.

Oxford Diffraction (2009). CrysAlis PRO. Oxford Diffraction Ltd, Yarnton, Oxfordshire, England.

Park, K., Evans, J. M. B. \& Myerson, A. S. (2003). Cryst. Growth Des. 3, 991-995.

Peintinger, M. F., Vilela Oliveira, D. \& Bredow, T. (2012). J. Comput. Chem. 34, 451-459.

Pham, H. Q., Mai, T. \& Pham-Tran, N.-N. (2014). J. Phys. Chem. C, 118, 4567-4577.

Poater, J., Solá, M. \& Bickelhaupt, F. M. (2006). Chem. Eur. J. 12, 2902-2905.

Politzer, P., Murray, J. S. \& Clark, T. (2013). Phys. Chem. Chem. Phys. 15, 11178-11189.

Prencipe, M. (1990). Laurea Thesis, pp. 87-89.

Raffo, P. A., Cukiernik, F. D. \& Baggio, R. F. (2015). Acta Cryst. C71, 84-88.

Raffo, P. A., Marcolongo, J., Funes, A., Baggio, R., Slep, L. D. \& Cukiernik, F. D. (2016). J. Mol. Struct. 1108, 235-244.

Rajamma, A. J., Sateesha, S. B., Narode, M. K., Prashanth, V. R. S. S. \& Karthik, A. M. (2015). Indian J. Pharm. Sci. 77, 34-40.

Reddy, C. M., Kirchner, M. T., Gundakaram, R. C., Padmanabhan, K. A. \& Desiraju, G. R. (2006). Chem. Eur. J. 12, 2222-2234.
Resnati, G., Boldyreva, E., Bombicz, P. \& Kawano, M. (2015). IUCrJ, 2, 675-690.

Rosokha, S. V., Stern, C. L. \& Ritzert, J. T. (2013). Chem. Eur. J. 19, 8774-8788.

Ruiz, B., Coe, B. J., Gianotti, R., Gramlich, V., Jazbinsek, M. \& Günter, P. (2007). CrystEngComm, 9, 772-776.

Šalitroš, I., Fuhr, O. \& Ruben, M. (2016). Materials, 9, 585.

Sarkar, S., Pavan, M. S., Cherukuvada, S. \& Row, T. N. G. (2016). Chem. Commun. 52, 5820-5823.

Sheldrick, G. M. (2008). Acta Cryst. A64, 112-122.

Sheldrick, G. M. (2015). Acta Cryst. C71, 3-8.

Spackman, M. (2015). Cryst. Growth Des. 15, 5624-5628.

Spek, A. L. (2009). Acta Cryst. D65, 148-155.

Thakur, T. S., Dubey, R. \& Desiraju, G. R. (2015). IUCrJ, 2, 159160.

Thallapally, P. K., Jetti, R. K. R., Katz, A. K., Carrell, H. L., Singh, K., Lahiri, K., Kotha, S., Boese, R. \& Desiraju, G. R. (2004). Angew. Chem. Int. Ed. Engl. 43, 1149-1155.

Torbeev, V. Y., Shavit, E., Weissbuch, I., Leiserowitz, L. \& Lahav, M. (2005). Cryst. Growth Des. 5, 2190-2196.

Tothadi, S., Joseph, S. \& Desiraju, G. R. (2013). Cryst. Growth Des. 13, 3242-3254.

Wang, G., Chen, Z., Xu, Z., Wang, J., Yang, Y., Cai, T., Shi, J. \& Zhu, W. (2016). J. Phys. Chem. B, 120, 610-620.

Weissbuch, I., Lahav, M. \& Leiserowitz, L. (2003). Cryst. Growth Des. 3, 125-150.

Weissbuch, I., Torbeev, V. Y., Leiserowitz, L. \& Lahav, M. (2005). Angew. Chem. Int. Ed. Engl. 44, 3226-3229.

Wenk, H. H. \& Sander, W. (2002). Eur. J. Org. Chem. pp. $3927-$ 3935. 


\title{
supporting information
}

Acta Cryst. (2017). C73, 667-673 [https://doi.org/10.1107/S2053229617011007]

Polymorphism of a widely used building block for halogen-bonded assemblies: 1,3,5-trifluoro-2,4,6-triiodobenzene

\author{
Pablo A. Raffo, Sebastián Suárez, Adolfo C. Fantoni, Ricardo Baggio and Fabio D. Cukiernik \\ Computing details
}

Data collection: CrysAlis PRO (Oxford Diffraction, 2009); cell refinement: CrysAlis PRO (Oxford Diffraction, 2009); data reduction: CrysAlis PRO (Oxford Diffraction, 2009); program(s) used to solve structure: SHELXS97 (Sheldrick, 2008); program(s) used to refine structure: SHELXL2014 (Sheldrick, 2015); molecular graphics: SHELXTL (Sheldrick, 2008); software used to prepare material for publication: SHELXL97, PLATON (Spek, 2009).

1,3,5-Trifluoro-2,4,6-triiodobenzene

Crystal data

$\mathrm{C}_{6} \mathrm{~F}_{3} \mathrm{I}_{3}$

$M_{r}=509.76$

Monoclinic, $P 2_{1} / c$

$a=9.3455(9) \AA$

$b=13.1854(10) \AA$

$c=9.2185(8) \AA$

$\beta=118.466(11)^{\circ}$

$V=998.61(18) \AA^{3}$

$Z=4$

\section{Data collection}

CCD Oxford Diffraction Xcalibur, Eos, Gemini diffractometer

Radiation source: Enhance (Mo) X-ray Source thick slices scans

Absorption correction: multi-scan

CrysAlisPro (Oxford Diffraction, 2009)

$T_{\min }=0.12, T_{\max }=0.42$

7952 measured reflections

\section{Refinement}

Refinement on $F^{2}$

Least-squares matrix: full

$R\left[F^{2}>2 \sigma\left(F^{2}\right)\right]=0.054$

$w R\left(F^{2}\right)=0.165$

$S=1.06$

2404 reflections

109 parameters

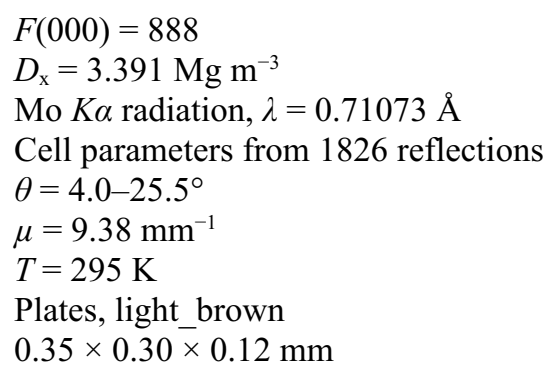

2404 independent reflections

1610 reflections with $I>2 \sigma(I)$

$R_{\text {int }}=0.075$

$\theta_{\max }=29.3^{\circ}, \theta_{\min }=4.0^{\circ}$

$h=-12 \rightarrow 12$

$k=-17 \rightarrow 17$

$l=-11 \rightarrow 11$ 


\section{Special details}

Geometry. All esds (except the esd in the dihedral angle between two 1.s. planes) are estimated using the full covariance matrix. The cell esds are taken into account individually in the estimation of esds in distances, angles and torsion angles; correlations between esds in cell parameters are only used when they are defined by crystal symmetry. An approximate (isotropic) treatment of cell esds is used for estimating esds involving l.s. planes.

Fractional atomic coordinates and isotropic or equivalent isotropic displacement parameters $\left(\AA^{2}\right)$

\begin{tabular}{lllll}
\hline & $x$ & $y$ & $z$ & $U_{\text {iso }} * / U_{\text {eq }}$ \\
\hline F1 & $0.3706(9)$ & $0.8880(5)$ & $0.1550(8)$ & $0.0477(17)$ \\
F3 & $0.5120(9)$ & $0.8418(5)$ & $0.7112(8)$ & $0.0454(16)$ \\
F5 & $0.9181(8)$ & $0.9031(6)$ & $0.5590(8)$ & $0.0468(17)$ \\
I2 & $0.19358(10)$ & $0.83570(7)$ & $0.36597(10)$ & $0.0513(3)$ \\
I4 & $0.89656(9)$ & $0.86728(6)$ & $0.88692(8)$ & $0.0414(3)$ \\
I6 & $0.71380(11)$ & $0.92451(7)$ & $0.17247(9)$ & $0.0504(3)$ \\
C1 & $0.4848(13)$ & $0.8838(7)$ & $0.3127(12)$ & $0.030(2)$ \\
C2 & $0.4352(13)$ & $0.8629(7)$ & $0.4307(13)$ & $0.031(2)$ \\
C3 & $0.5582(15)$ & $0.8611(7)$ & $0.5956(13)$ & $0.033(2)$ \\
C4 & $0.7199(13)$ & $0.8721(7)$ & $0.6403(11)$ & $0.029(2)$ \\
C5 & $0.7587(15)$ & $0.8916(7)$ & $0.5171(13)$ & $0.034(2)$ \\
C6 & $0.6472(15)$ & $0.8977(9)$ & $0.3549(13)$ & $0.037(3)$ \\
\hline
\end{tabular}

Atomic displacement parameters $\left(\AA^{2}\right)$

\begin{tabular}{lllllll}
\hline & $U^{11}$ & $U^{22}$ & $U^{33}$ & $U^{12}$ & $U^{13}$ & $U^{23}$ \\
\hline F1 & $0.034(4)$ & $0.069(5)$ & $0.033(3)$ & $0.000(3)$ & $0.011(3)$ & $0.008(3)$ \\
F3 & $0.046(4)$ & $0.061(4)$ & $0.035(3)$ & $0.001(3)$ & $0.024(3)$ & $0.008(3)$ \\
F5 & $0.028(4)$ & $0.078(5)$ & $0.036(3)$ & $-0.005(3)$ & $0.017(3)$ & $-0.002(3)$ \\
I2 & $0.0323(5)$ & $0.0693(6)$ & $0.0482(5)$ & $-0.0118(4)$ & $0.0159(4)$ & $0.0070(4)$ \\
I4 & $0.0357(5)$ & $0.0575(5)$ & $0.0285(4)$ & $0.0021(4)$ & $0.0133(4)$ & $-0.0048(3)$ \\
I6 & $0.0451(6)$ & $0.0762(6)$ & $0.0369(5)$ & $0.0089(4)$ & $0.0252(4)$ & $0.0140(4)$ \\
C1 & $0.025(6)$ & $0.029(5)$ & $0.022(5)$ & $0.006(5)$ & $0.001(4)$ & $0.004(4)$ \\
C2 & $0.024(5)$ & $0.037(5)$ & $0.029(5)$ & $-0.003(5)$ & $0.009(5)$ & $0.006(4)$ \\
C3 & $0.038(6)$ & $0.036(6)$ & $0.031(5)$ & $0.005(5)$ & $0.021(5)$ & $0.003(4)$ \\
C4 & $0.030(6)$ & $0.032(5)$ & $0.021(5)$ & $0.000(5)$ & $0.008(4)$ & $0.002(4)$ \\
C5 & $0.038(6)$ & $0.027(5)$ & $0.039(6)$ & $0.001(5)$ & $0.020(5)$ & $-0.007(4)$ \\
C6 & $0.038(7)$ & $0.050(6)$ & $0.025(5)$ & $-0.011(5)$ & $0.017(5)$ & $-0.006(4)$ \\
& & & & & &
\end{tabular}

Geometric parameters $\left(\AA,{ }^{\circ}\right)$

\begin{tabular}{llll}
\hline $\mathrm{F} 1-\mathrm{C} 1$ & $1.333(11)$ & $\mathrm{C} 1-\mathrm{C} 2$ & $1.398(14)$ \\
$\mathrm{F} 3-\mathrm{C} 3$ & $1.351(11)$ & $\mathrm{C} 1-\mathrm{C} 6$ & $1.387(15)$ \\
$\mathrm{F} 5-\mathrm{C} 5$ & $1.358(14)$ & $\mathrm{C} 2-\mathrm{C} 3$ & $1.402(14)$ \\
$\mathrm{I} 2-\mathrm{C} 2$ & $2.074(11)$ & $\mathrm{C} 3-\mathrm{C} 4$ & $1.371(15)$ \\
$\mathrm{I} 4-\mathrm{C} 4$ & $2.079(10)$ & $\mathrm{C} 4-\mathrm{C} 5$ & $1.371(14)$ \\
$\mathrm{I} 6-\mathrm{C} 6$ & $2.083(10)$ & $\mathrm{C} 5-\mathrm{C} 6$ & $1.358(15)$ \\
& & & $117.4(10)$
\end{tabular}




$\begin{array}{llll}\mathrm{F} 1-\mathrm{C} 1-\mathrm{C} 6 & 120.1(9) & \mathrm{C} 5-\mathrm{C} 4-\mathrm{I} 4 & 121.7(8) \\ \mathrm{C} 2-\mathrm{C} 1-\mathrm{C} 6 & 122.1(9) & \mathrm{C} 3-\mathrm{C} 4-\mathrm{I} 4 & 120.8(7) \\ \mathrm{C} 1-\mathrm{C} 2-\mathrm{C} 3 & 116.3(10) & \mathrm{C} 6-\mathrm{C} 5-\mathrm{C} 4 & 123.8(11) \\ \mathrm{C} 1-\mathrm{C} 2-\mathrm{I} 2 & 122.0(8) & \mathrm{C} 6-\mathrm{C} 5-\mathrm{F} 5 & 118.0(9) \\ \mathrm{C} 3-\mathrm{C} 2-\mathrm{I} 2 & 121.8(7) & \mathrm{C} 4-\mathrm{C} 5-\mathrm{F} 5 & 118.2(10) \\ \mathrm{F} 3-\mathrm{C} 3-\mathrm{C} 4 & 120.2(10) & \mathrm{C} 5-\mathrm{C} 6-\mathrm{C} 1 & 117.6(9) \\ \mathrm{F} 3-\mathrm{C} 3-\mathrm{C} 2 & 117.0(10) & \mathrm{C} 5-\mathrm{C} 6-\mathrm{I} 6 & 122.1(9) \\ \mathrm{C} 4-\mathrm{C} 3-\mathrm{C} 2 & 122.7(9) & \mathrm{C} 1-\mathrm{C} 6-\mathrm{I} 6 & 120.3(8)\end{array}$

